\title{
Spatial Evaluation of the Effects of Sun Radiation and Clothing Adaptation in Indoor Comfort Simulations
}

\author{
Jorge Conejo Fernández ${ }^{1}$, Francesca Cappelletti ${ }^{2}$, Andrea Gasparella ${ }^{1}$ \\ ${ }^{1}$ Free University of Bolzano, Bolzano, Italy \\ ${ }^{2}$ University IUAV of Venice, Venice, Italy
}

\begin{abstract}
Changes in clothing are one of the most effective adaptation mechanisms that occupants have to improve their personal level of satisfaction in the indoor environment. This can play a crucial role when considering daily variation or uneven conditions as it happens in case of solar radiation entering the room. Nevertheless, when simulation is conducted to assess thermal comfort, clothing is often assumed constant throughout the day or the season.

The goal of this work is two-fold: on one hand, it aims at assessing the potential of clothing adaptation for providing comfort in the presence of solar radiation. On the other hand, it evaluates the sensitivity to clothing adaptation of the categorization of buildings according to the standards ISO 7730 and EN 15251, in order to assess the impact of simplified clothing assumptions on the analysis of comfort.

Five clothing scenarios have been compared: four of them are given by a combination of two different strategies for daily selection of clothing and two adaptation ranges for hourly changes; the fifth one is a reference one, which assumes clothing is fully adaptable from 0.5 to 1.0 . For the comparison, a thermal model of a $100 \mathrm{~m}^{2}$ shoebox office located in Milan (Italy) is used. The scenarios are calculated for a grid of points distributed in the space and the results are reported using two long-term metrics: Thermal Comfort Availability (TCA) and Thermal Comfort Usability (TCU). Comfort is assessed according to Fanger model, both standard and modified to account for solar radiation directly on the occupant.
\end{abstract}

\section{Introduction}

Thermal comfort can be defined as the "condition of mind that expresses satisfaction with the thermal environment and is assessed by subjective evaluation" (ASHRAE, 2017). It is normally evaluated by means of surveys in occupied buildings, and with thermal simulation and thermal comfort models during the building design phase.

Two main groups of thermal comfort models can be distinguished in literature: heat balance models, which rely on mathematical models of the human body and require specific inputs regarding personal variables (metabolic rate and clothing) and; adaptive models, which were obtained from field surveys in unconditioned spaces and predict comfort temperature ranges rather than people satisfaction response. Adaptive models are suggested for buildings without mechanical cooling systems. Both heat balance (ASHRAE, 2017; CEN, 2007; ISO, 2005) and adaptive models (ASHRAE, 2017; CEN, 2007) are included in international standards.

According to the Fanger thermal comfort model (Fanger, 1970), the only heat balance model included in international standards (ASHRAE, 2017; CEN, 2007; ISO, 2005) and probably the most frequently used model, thermal comfort is function of six variables: four environmental and two personal. The former ones define the thermal environment, air temperature, mean radiant temperature, relative humidity, and air velocity, and are often not completely under the occupant's control. The two personal variables, i.e. metabolic rate and clothing insulation, even though may also be given by external requirements, such as dress code, are adaptable to a certain extent and can also be different from person to person to a certain degree, in line with the considerations of the adaptive models. Fanger model (Fanger, 1970), shows a significant sensitivity to the personal parameters (Gauthier \& Shipworth, 2012). Nevertheless, in the assessment and simulations they are quite often considered constant within the same day or even the same season, and uniform in space for all the occupants, with values suggested by the standards (ASHRAE, 2017; ISO, 2005).

As regards metabolic rate, studies suggest that it is rarely changed in the work environment for adaptation purposes (Haldi \& Robinson, 2008) and that people rather tend to compensate internal heat production with the use of drinks (Baker \& Standeven, 1996; Haldi \& Robinson, 2011). Clothing insulation adaptation on the other hand is used more often and at different levels. Firstly, there is a day-to-day selection of clothing when people leave home in the morning. Secondly, there are clothing adjustments during the day, such as the removal or addition of garments, or even smaller changes such as rolling up sleeves.

Baker and Standeven (1996) observing 1500 hours of data from different subjects in offices found that $75 \%$ of times outdoor thermal conditions had affected the choice of clothes in the morning, while during 864 working hours there were $62(7.2 \%)$ adjustments of clothing level.

Wyon \& Holmberg (1972), as cited by Newsham (1997), observed the clothing choices of children between 9 and 11 years old and found significant hourly changes. They concluded that clothing insulation should be evaluated in 
the short term.

Newsham \& Tiller (1995) conducted a field study of thermal comfort in offices using questionnaires. Daily clothing was found depending only on the expected indoor environment, and that $14.7 \%$ of participants had made minor or major changes to their clothing during the hour prior to the questionnaire.

De Carli et al. (2007) studied the clothing behavior of people based of existing databases finding that the daily choice of clothing is mainly influenced by the outdoor temperature at $6 \mathrm{a} . \mathrm{m}$. Changes of clothing during the day, when possible, are influenced by indoor air temperature. They also found that in conditioned buildings, it is normal that occupants adjust their clothing up to 0.2 clo, corresponding to the insulation of a jacket or sweater.

Haldi \& Robinson (2011) conducted a field survey in an office building in Switzerland looking for a model capable of predicting clothing choices. Clothing was found to be described by the daily mean outdoor temperature. Major clothing changes occur rarely (only $2.1 \%$ of hours) during the day, even if minor clothing adaptations are possible.

Although the low percentages of adjustments depicted from the previous studies, clothing adaptation to tackle discomfort has been object of several studies implemented by means of simulation, also because of the implications that people's capacity of adaptation can have on the indoor temperature range that the system has to maintain and on the energy saving of the building.

Newsham (1997) simulated the effect of clothing adjustment and evaluated whether its impact is significant in comfort and energy simulations. He derived setpoint temperatures according to the level of clothing adaptation, and then performed annual simulations with those setpoints to evaluate the energy consumption of the different alternatives. He concluded that clothing adjustments should be considered in building computer simulation as a strategy to improve comfort and energy efficiency.

De Carli et al. (2007) performed computer simulations for a typical air-conditioned office and found that variations of 0.1 clo can significantly affect the indoor comfort evaluation.

Schiavon \& Lee (2013) used 6333 observations from ASHRAE RP-884 (de Dear \& Brager, 1998) and ASHRAE RP-921 (Cena \& de Dear, 1998) to develop two dynamic predictive models of clothing insulation, one of which was slightly modified with the aim of including it in thermal comfort standards. According to their analysis, and in agreement with de Carli et al. (2007), daily clothing selection was more correlated with outdoor temperature at 6 a.m.

One of the possible drivers for clothing adaptation in indoor environment is the uneven and variable distribution of solar radiation entering the space. Its effect can be described in terms of localized and short time variations of the mean radiant temperature, which can be included in the Fanger model (Fanger, 1970) according to La Gennusa et al. (2005).

In this work, standard evaluations based on fixed clothing levels for the whole working day have been compared with more realistic hourly clothing adaptation driven by discomfort. Two main approaches for the standard clothing levels have been considered: the seasonal clothing level (i.e. 0.5 clo during the cooling season and 1 clo during the heating season) and the dynamic clothing level described in Schiavon \& Lee (2013). These have been taken as reference in order to assess the impact of hourly clothing adaptation on the improvement of the thermal comfort conditions. Thermal discomfort caused by sun radiation entering through the windows has been considered in order to emphasize the time variability of the conditions and the space unevenness.

Five different scenarios are compared with the aim of assessing the potential of clothing adaptation, and the possible improvement in comfort analysis and building quality categorization according to the standards ISO 7730 (ISO, 2005) and EN 15251 (CEN, 2007).

Comfort is analyzed in different positions and for a whole year for an open space office located in Milan (Italy). Results are reported in terms of Thermal Comfort Availability (TCA) and Thermal Comfort Usability (TCU) (Atzeri et al., 2016), based on Fanger model, including or no the contribution of solar radiation ( $\mathrm{La}$ Gennusa et al., 2005). TCA and TCU will be further described in the methods section of this document.

\section{Methods}

\section{Clothing adjustments}

The clothing scenarios compared are presented in Table 1 , and described below.

1. Seasonal. The clothing level changes only seasonally, as in common building computer simulation, in agreement with the standards (ASHRAE, 2017; ISO, 2005). In summer occupants wear 0.5 clo all day long, while in winter 1.0 clo. Summer lasts from April $1^{\text {st }}$ to September $30^{\text {th }}$.

2. Adaptive seasonal. Reference clothing for each day is selected according to the seasonal scenario (0.5/1.0 clo). In summer, occupants can perform small clothing changes $(+0.1$ clo) or add a garment $(+0.2$ clo) to the summer clothing $(0.5 \mathrm{clo})$ if that improves their comfort; no lower clothing level is allowed due to the dress code imposed in offices. Similarly, they can also adjust their clothing ( -0.1 clo) or remove a garment $(-0.2$ clo $)$ in winter, since the maximum value for an office activity is assumed to be 1.0 clo. This approach agrees with the clothing adaptation that De Carli et al. (2007) observed.

3. Fully adaptive. Occupants are totally free to select the clothing that provides best comfort at any hour, from 0.5 to 1.0 clo. This is a reference scenario included here to see the theoretical optimum range of clothing and to contrast it with other, more realistic scenarios. 
Table 1: Simulated clothing adaptation scenarios

\begin{tabular}{|c|l|c|c|c|}
\hline$\#$ & Scenario & Type & Daily Clothing selection & Hourly Adjustment \\
\hline 1 & Seasonal & Seasonal & 0.5 in winter $/ 1.0$ in summer & - \\
\hline 2 & Adaptive Seasonal & Seasonal & 0.5 in winter $/ 1.0$ in summer & -0.2 clo in winter $/+0.2$ clo in summer \\
\hline 3 & Adaptive & Seasonal & $0.5-1.0$ & 0.5 clo -1.0 clo \\
\hline 4 & Dynamic & Statistical & Dynamic clothing model (Schiavon \& Lee, 2013) & - \\
\hline 5 & Adaptive Dynamic & Statistical & Dynamic clothing model (Schiavon \& Lee, 2013) & -0.2 clo $/+0.2$ clo \\
\hline
\end{tabular}

Table 2: Thermo-physical properties of the opaque envelope

\begin{tabular}{|c|c|c|c|c|c|c|c|}
\hline Construction & Material & Thickness & Conductivity & Density & Specific Heat & Emissivity & $\begin{array}{c}\text { Solar } \\
\text { Absorptance }\end{array}$ \\
\hline $\begin{array}{c}\text { Opaque } \\
\text { Envelope }\end{array}$ & Insulation & $0.12 \mathrm{~m}$ & $0.037 \mathrm{~W} \mathrm{~m}^{-1} \mathrm{~K}^{-1}$ & $125 \mathrm{~kg} \mathrm{~m}^{-3}$ & $1030 \mathrm{~J} \mathrm{~kg} \mathrm{~K}^{-1}$ & 0.9 & 0.3 \\
\cline { 2 - 8 } & Clay Block & $0.2 \mathrm{~m}$ & $0.432 \mathrm{~W} \mathrm{~m}^{-1} \mathrm{~K}^{-1}$ & $1200 \mathrm{~kg} \mathrm{~m}^{-3}$ & $840 \mathrm{~J} \mathrm{~kg} \mathrm{~K}^{-1}$ & 0.9 & 0.7 \\
\hline
\end{tabular}

4. Dynamic. Daily clothing is selected according to the dynamic clothing model that Schiavon \& Lee (2013) proposed to be included in thermal comfort standards. This is a pseudo-realistic approach, with clothing level determined by statistic analysis of a big dataset of observations. There is no hourly clothing adaptation in this scenario.

5. Adaptive dynamic. Daily clothing is selected according to the previous dynamic clothing model (Schiavon \& Lee, 2013) but occupants can increase or decrease their clothing by 0.1 or 0.2 clo, up to a maximum of 1.0 clo in winter and a minimum of 0.46 clo in summer, according to the limits of the dynamic clothing model.

\section{Office simulation settings}

The building energy model of an open space office (Figure 1) has been implemented in EnergyPlus (U.S. Department of Energy, 2018). The weather data used in the simulation is a typical meteorological year (TMY) of Milan (Italy) taken from the database of the International Weather for Energy Calculations (IWEC) (ASHRAE, 2001).

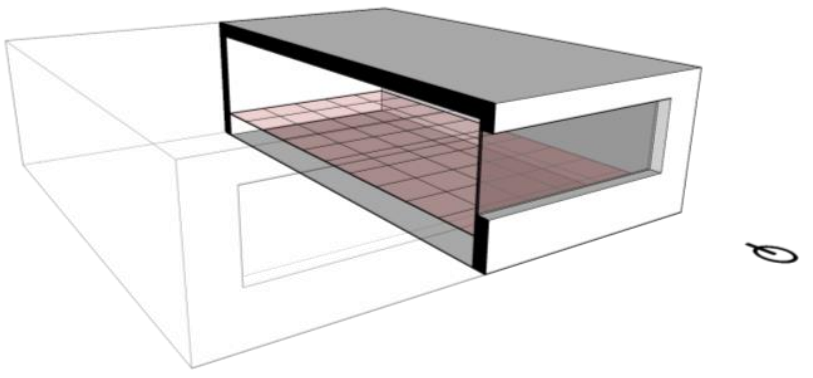

Figure 1: Vertical section of the standard open office space with the analysis grid (in red)

Vertical walls and the roof are exposed to the outdoors (Table 2), while the floor is considered adiabatic. The south-facing window is made of a double glazing ( $U_{g}=$ $1.26 \mathrm{~m}^{-2} \mathrm{~K}^{-1}$ ) with a Solar Heat Gain Coefficient (SHGC) of 0.7. No solar shadings are considered, because of the aim of evaluating the maximum levels of exposure.

The comfort is assessed in a horizontal grid with $1 \mathrm{~m}$ distance between points, at a height of $0.6 \mathrm{~m}$ from the ground (Figure 1). General simulation settings are described in Table 3.
Table 3: Simulation settings

\begin{tabular}{|l|c|}
\hline Simulation Settings & Value \\
\hline Floor area & $100 \mathrm{~m}^{2}$ \\
\hline Height & $3 \mathrm{~m}$ \\
\hline Window Area & $13.5 \mathrm{~m}^{2}(9 \mathrm{~m} \mathrm{x} 1.5 \mathrm{~m})$ \\
\hline Occupancy Period & Monday to Friday \\
\hline Occupancy Hours & 8 am to $6 \mathrm{pm}$ \\
\hline $\begin{array}{l}\text { Hours of Operation of } \\
\text { HVAC }\end{array}$ & $\begin{array}{l}\text { Heating: } 6 \text { am to } 6 \mathrm{pm} ; \\
\text { Cooling: } 7 \text { am to } 7 \mathrm{pm}\end{array}$ \\
\hline $\begin{array}{l}\text { Occupancy Density (UNI } \\
\text { 10339:1995, 1995) }\end{array}$ & 0.12 people $\mathrm{m}^{-2}$ \\
\hline Occupants Activity & 1.2 met \\
\hline Vapor production rate & $0.05 \mathrm{~kg} \mathrm{~h}{ }^{-1}$ \\
\hline Ventilation Rate & $\begin{array}{c}\text { Occupied: } 1.58 \mathrm{ACH} ; \\
\text { Unoccupied: } 0.05 \mathrm{ACH}\end{array}$ \\
\hline $\begin{array}{l}\text { Internal Gains } \\
\text { (EN ISO 13790:2008, } \\
2008)\end{array}$ & $\begin{array}{c}\text { Occupied: } 20 \mathrm{~W} \mathrm{~m} \mathrm{~m}^{-2} ; \\
\text { Unoccupied: } 2 \mathrm{~W} \mathrm{~m}^{-2}\end{array}$ \\
\hline Heating Setpoint & Winter: $20^{\circ} \mathrm{C} ;$ Summer: $23^{\circ} \mathrm{C}$ \\
\hline Cooling Setpoint & Winter: $24^{\circ} \mathrm{C}$; Summer: $26^{\circ} \mathrm{C}$ \\
\hline Setback Temperatures & Heating: $15^{\circ} \mathrm{C}$; Cooling: $28^{\circ} \mathrm{C}$ \\
\hline Humidity Control & Not available \\
\hline
\end{tabular}

\section{Solar radiation correction}

Thermal comfort in each clothing scenario has been evaluated twice: (i) according to the Fanger model (Fanger, 1970) as detailed in ISO 7730 (ISO, 2005), and (ii) considering the effect of solar radiation on the occupant. These scenarios are labeled "standard" and "irradiated", respectively.

The correction to the Fanger model for solar radiation is obtained through a modified mean radiant temperature, according to the approach by La Gennusa et al. (2005).

\section{Comfort metrics}

Annual or spatial results are presented by means of two metrics, as defined in Atzeri et al. (2016): Thermal Comfort Availability (TCA) and Thermal Comfort Usability (TCU).

TCA is the local time availability of thermal comfort in the selected period, corresponding to PPD values less than or equal to $10 \%$, as suggested by the technical standards (CEN, 2007; ISO, 2005). The mathematical expression of TCA in this case can be given as:

$$
\mathrm{TCA}=\sum_{j=1}^{N t} w f_{j} \frac{1}{N t} \in[0,1] w f_{j}=\left\{\begin{array}{l}
1 \text { if } \mathrm{CI} \leq 10 \\
0 \text { if } \mathrm{CI}>10
\end{array}(1)\right.
$$


where CI represents the comfort indicator used (i.e. PPD) in a specific point and time, and $\mathrm{Nt}$ is the total number of working hours in one year. In this study CI is calculated during the working hours ( 8 am to $6 \mathrm{pm}$ ) of workdays for a whole year. Calculation timestep is 1 hour.

TCU expresses the usability of the space, in terms of the fraction of it with an adequate thermal comfort in a given moment, i.e. when PPD is less than or equal to $10 \%$ :

$$
\mathrm{TCU}=\sum_{j=1}^{N p} w f_{j} \frac{1}{N p} \in[0,1] w f_{j}=\left\{\begin{array}{l}
1 \text { if } \mathrm{CI} \leq 10 \\
0 \text { if } \mathrm{CI}>10
\end{array}(2)\right.
$$

with $\mathrm{Np}$ the total number of points in the space where the comfort index is calculated.

\section{Categories of thermal environment}

In this work, thermal comfort is assessed according to categories B and C of the standard ISO 7730 (ISO, 2005), which correspond to categories II and III of the standard EN 15251 (CEN, 2007) (Table 4). In particular, category III/C has been considered because the reference standard does not account for solar radiation on the occupants in assessing comfort. This way, it has been possible to consider the effects of a higher occupants' tolerance on the evaluation of the indoor environment. Category I/A is not considered, since it is reserved to buildings "occupied by very sensitive and fragile persons", which is out of the scope of this work. Some authors also argued that such a level of precision in comfort simulations and such a strict control of thermal environment is doable with a standard heating, ventilation and air conditioning (HVAC) system (Arens et al., 2010).

Table 4: Comfort categories in standards ISO 7730 (ISO, 2005) and EN 15251 (CEN, 2007)

\begin{tabular}{|c|c|c|}
\hline \multicolumn{2}{|c|}{ Categories } & \multirow{2}{*}{ Required PMV } \\
\cline { 1 - 2 } ISO 7730 & EN 15251 & \\
\hline A & I & $-0.2<$ PMV $<+0.2$ \\
\hline B & II & $-0.5<$ PMV $<+0.5$ \\
\hline C & III & $-0.7<$ PMV $<+0.7$ \\
\hline
\end{tabular}

\section{Results and Discussion}

In Figure 2 to 7, the performance of the standard scenarios is represented on the left-hand side, while those including the effect of solar radiation are on the right-hand side.

\section{Thermal comfort availability}

Figure 2 reports the TCA for category II/B (CEN, 2007; ISO, 2005) on the analysis grid, for the different clothing scenarios .

Seasonal standard scenario shows a very high TCA (around $90 \%$ ) for almost all the points, but those closer to the center of the window, which present values between $65 \%$ and $80 \%$. When solar radiation is considered, TCA goes down to $35-55 \%$ in the same area. While in the seasonal standard, comfort is reduced up to two meters from the window, in the seasonal irradiated it is affected much deeper, up to 5 meters from the window.

Adaptive seasonal and fully adaptive have almost identical values of TCA, and a similar distribution to that of seasonal. Both of them present a point by point improvement of around 5-10\% with respect to the seasonal scenario, which indicates that clothing changes of 0.2 clo are sufficient to affect significantly comfort evaluation in the category II/B. However, it is still not enough to fully compensate for the effect of solar radiation close to the window.

TCA percentages in dynamic standard and dynamic irradiated scenarios are much lower. In general, the daily levels of clothing do not appear to suit the indoor temperatures setpoints, providing larger discomfort than the seasonal one. Dynamic standard has a TCA of around $65 \%$ in the center of the room, and between $35 \%$ and 55 $\%$ closer to the window. In dynamic irradiated the influence of the window is extended up to 6 meters deeper in the space, and TCA is reduced to $25-40 \%$.

In the adaptive dynamic standard scenario, TCA is uniformly distributed with a value around $90 \%$. Adaptive dynamic irradiated presents the same TCA in most of the space, except for the 2 meters closer to the window, where TCA drops to $45-75 \%$. When clothing adaptation is considered, TCA results calculated with the dynamic clothing model are equivalent to those obtained with a seasonal dynamic approach.

Adaptive dynamic has better TCA closer to the window than adaptive seasonal lower minimum clothing level ( 0.46 clo instead of $0.5 \mathrm{clo})$.

Figure 3 reports on the analysis grid the TCA for category III/C (CEN, 2007; ISO, 2005) for the different clothing scenarios. This has been considered to verify the possibility of relaxing the demanding requisites of category II/B, when solar radiation is taken into account.

Seasonal, adaptive seasonal, fully adaptive and adaptive dynamic present almost the same TCA. All four standard scenarios present $100 \%$ TCA almost all over the analysis grid, while in the irradiated scenarios TCA is reduced closer to the window, where it drops to around 70-80\%. In this category, all these scenarios provide consistent results in the comfort evaluation of the space.

Quite differently, TCA results for dynamic standard and irradiated present lower percentages, even if the distribution is similar to the other scenarios. TCA values in dynamic standard are around $85 \%$. In dynamic irradiated this percentage is reduced to $55-65 \%$ in the area closer to the window.

\section{Thermal comfort usability}

TCU temporal maps for a whole year are reported in Figure 4 for category II/B and in Figure 5 for category III/C (CEN, 2007; ISO, 2005). The horizontal axis represents the months of the year, and the vertical axis the hours of the day.

As regards category $\mathrm{II} / \mathrm{B}$, TCU for seasonal standard is generally high (around $90 \%$ of space is in comfort in each moment), except in some weeks of spring and autumn, when the percentage is less than $10 \%$, because of the assumption of a fix clothing level for the entire heating and cooling seasons in combination with the weather conditions during mid-seasons.

The temporal map of seasonal irradiated is very similar to the standard, but TCU is reduced between $50 \%$ and $70 \%$ in summer due to the entering solar radiation. 

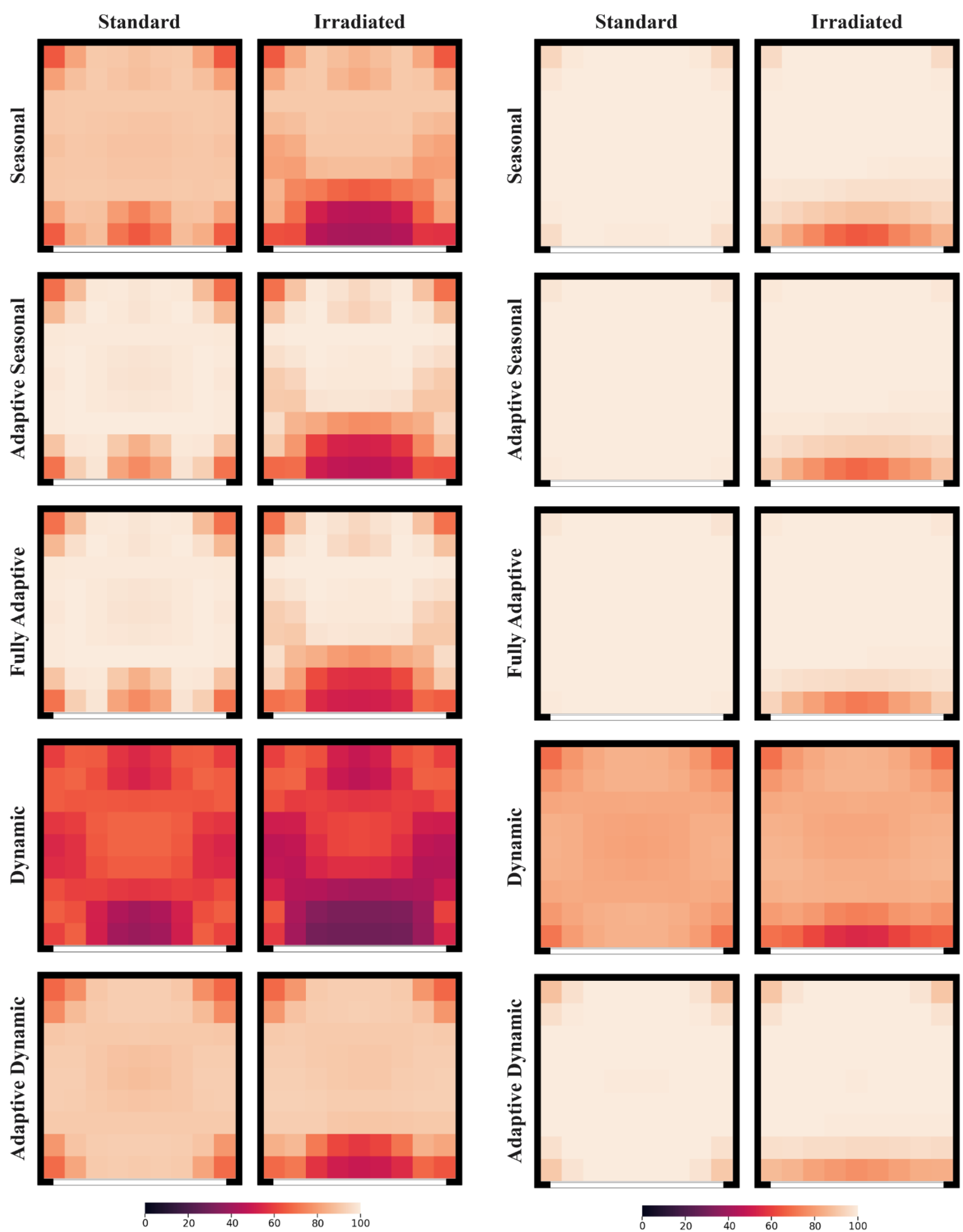

Figure 2: Floor plans of the office with the analysis grid, showing Thermal Comfort Availability (TCA), category II/B (CEN, 2007; ISO, 2005), of standard (left column) and irradiated PMV (right column) for the whole year.

Figure 3: Floor plans of the office with the analysis grid, showing Thermal Comfort Availability (TCA), category III/C (CEN, 2007; ISO, 2005), of standard (left column) and irradiated PMV (right column) for the whole year. 

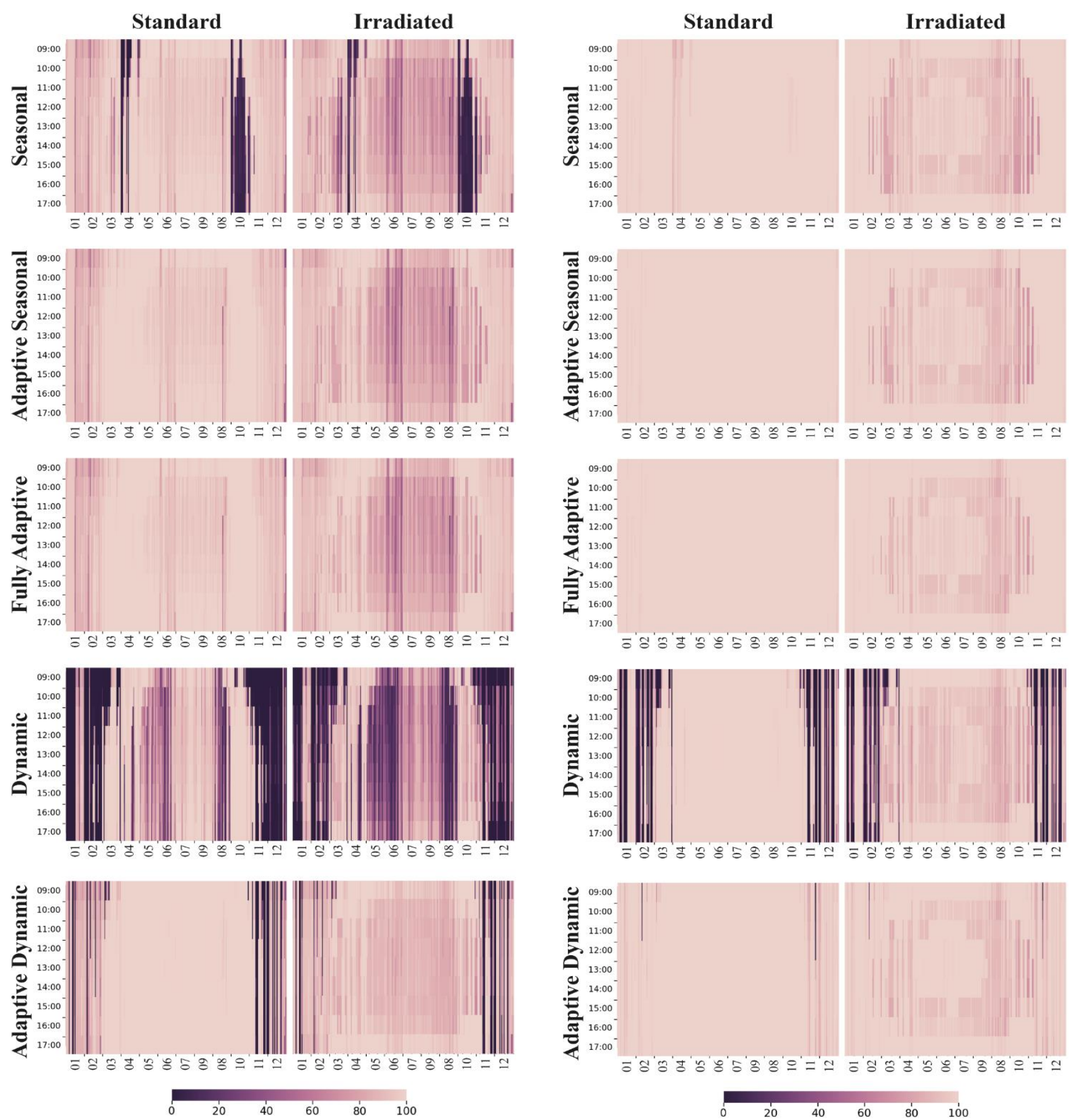

Figure 4: Temporal maps of Thermal Comfort Usability, category II/B (CEN, 2007; ISO, 2005), of standard (left column) and irradiated indexes (right column) for the whole year.

TCUs of adaptive seasonal and fully adaptive are almost identical to the seasonal during most of the year.

The clothing adaptation of these scenarios has proved effective to avoid the low comfort percentages during mid-seasons, but it was not able to raise the comfort percentages during summer because in all three cases the minimum level of clothing is the same $(0.5$ clo $)$. The dynamic scenario shows very low TCU values for a considerable amount of time, especially in winter. It seems that the model foresees clothing lower than advisable for the considered setpoints.

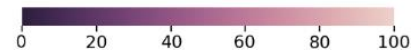

Figure 5: Temporal maps of Thermal Comfort Usability

(TCU, category III/C (CEN, 2007; ISO, 2005), of standard (left column) and irradiated indexes (right column) for the whole year

This situation is improved by adaptive dynamic, which has TCU higher than the non-dynamic scenarios during summer, but still many hours of discomfort during winter. In this season, the allowed hourly changes are not enough to compensate for the daily clothing choice.

Similarly to what has been seen in TCA, for the category III/C, seasonal, adaptive seasonal, fully adaptive and adaptive dynamic present almost the same results. In the standard analysis, all of them present a $100 \%$ TCU during the vast majority of time. In the irradiated analysis, TCU is reduced to around $70 \%$ in the central months of the year, mainly during morning and late afternoon. 
TCU for the dynamic scenario are similar during summer, but much lower during winter, where it decreases to $10 \%$ for the most of it. Not even in this category, adaptive dynamic clothing model is enough to compensate for the daily reference clothing.

\section{Annual cumulative distribution function of TCU}

Figure 6 shows the TCU annual duration plot for (a) category II/B and (b) category III/C (CEN, 2007; ISO, 2005), of all scenarios. Distribution of TCU values in adaptive seasonal and fully adaptive is almost identical, with the $90^{\text {th }}$ percentile over $90 \%$ in the standard version and around $70 \%$ in the irradiated version. Seasonal has a very similar distribution to the previous ones, with a TCU percentage around 5-10\% lower, as we observed in the TCA analysis grid. Dynamic and adaptive dynamic are different from the previous scenarios. TCU of dynamic standard presents the $50^{\text {th }}$ percentile over $80 \%$, while its irradiated version is more regularly distributed, with the $50^{\text {th }}$ percentile around $55 \%$. Adaptive dynamic standard and irradiated are both very polarized, with the $90^{\text {th }}$ percentile of the TCU values over $80 \%$.
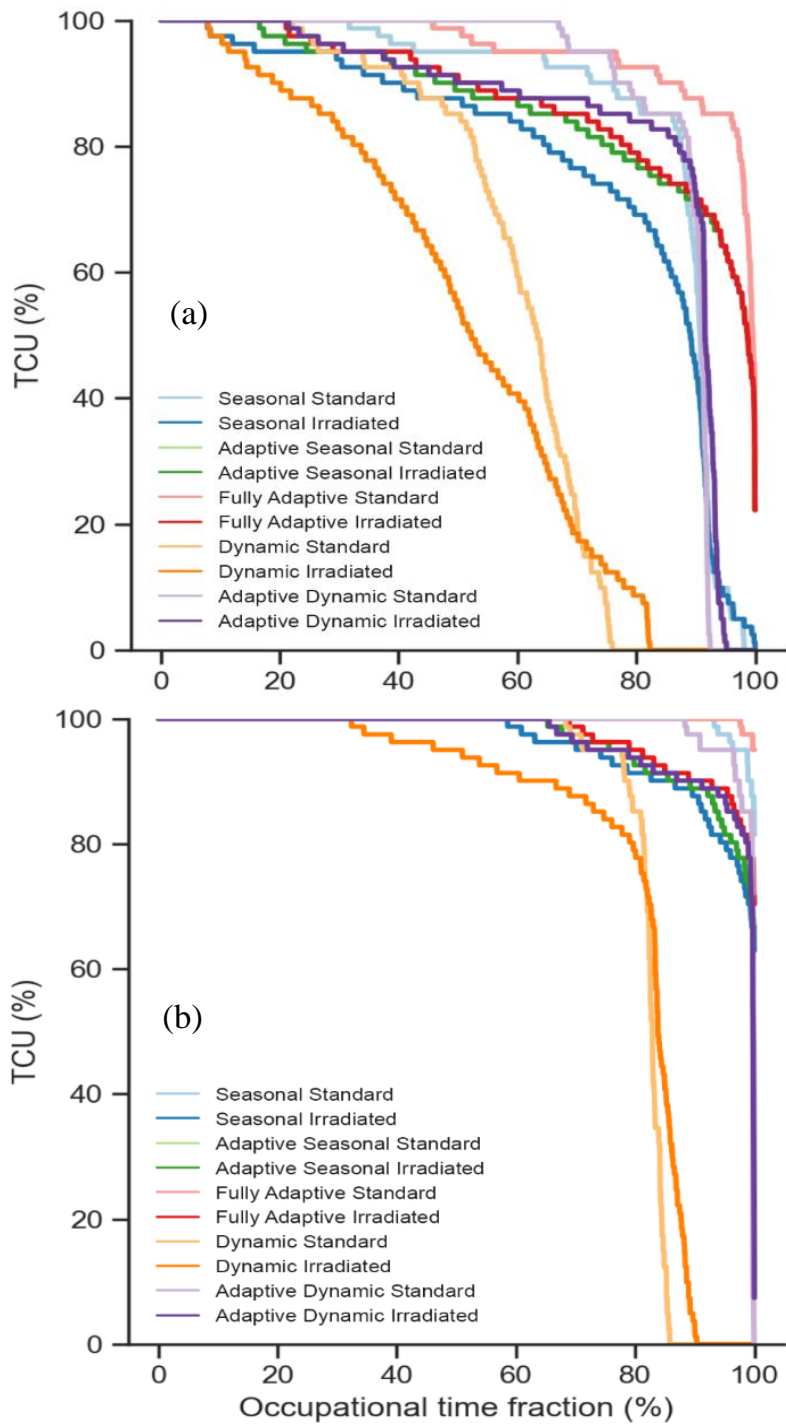

Figure 6: Cumulative distribution function of TCU, for (a) category II/C and (b) category III/C (CEN, 2007; ISO, 2005), of all the clothing scenarios
Differences provided by clothing adaptation scenarios in this category are very small (0-10\%) in seasonal, adaptive seasonal, adaptive and dynamic adaptive.

All of them have high TCU, with the $100^{\text {th }}$ percentile over $70 \%$. Dynamic presents a similar distribution, but for a percentage of occupational time lower of about $20 \%$. In this case, the $80^{\text {th }}$ percentile is slightly over $70 \%$.

\section{Clothing adaptation}

Figure 7 shows the maximum clothing difference between two different points of the analysis grid at a given moment in time, for the whole year for the adaptive scenarios.

In general, clothing differences are higher during midseasons: in March/April and October/November. In the irradiated models, clothing adaptation is also performed in winter during the central hours of the day.

While fully adaptive and adaptive seasonal have similar TCA and TCU percentages, the clothing in each of them is considerably different. In fact, fully adaptive uses most of all its adaptation range of clothing, up to 0.5 clo. This suggests that even though in the tested comfort categories (II/B and III/C) there was no significant difference, under more restrictive requirements (category I/A), fully adaptive could provide higher percentages of TCA and TCU.
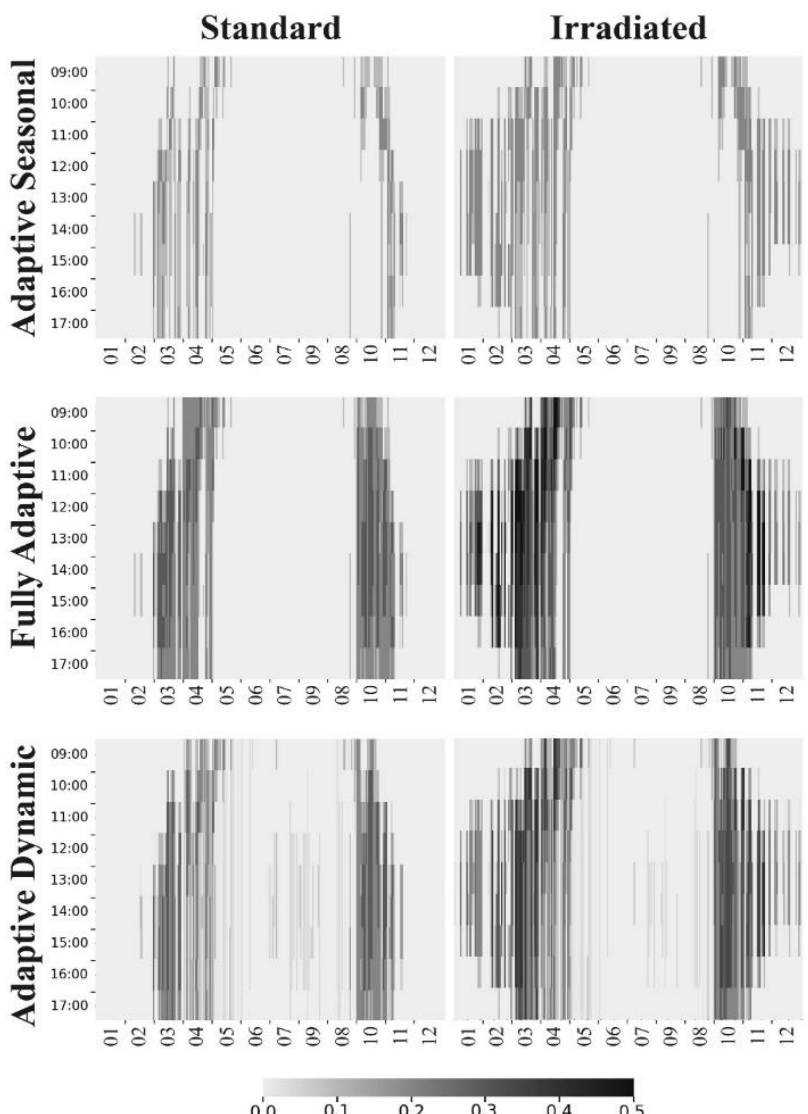

Figure 7: Maximum clothing difference among points (occupants) in the analysis grid at a given moment in time, for the whole year.

\section{Conclusion}

This work has investigated different clothing adaptation options in building comfort simulations, with and without 
taking into account solar radiation on the occupants. Furthermore, it analyses how the different approaches affect the evaluation of buildings with respect to the categories of standards EN 15251 (CEN, 2007) and ISO 7730 (ISO, 2005).

Clothing adaptation can improve comfort over the space all year long, but not enough to control discomfort due to solar radiation closer to the window, which has to be limited through shading strategies also adopted for visual comfort. A maximum clothing adaptation of 0.2 clo, like that observed in buildings (de Carli et al., 2007), seems enough to provide a TCA improvement of around $10 \%$ in the comfort category II/B.

If expectations are lower, as with category III/C, the benefit from clothing adaptation close to the windows is higher. The dynamic clothing model, seems to get larger improvement from clothing adaptation, probably to correct a general mismatching with the considered setpoint.

It is presumed that clothing changes would not be sufficient to guarantee comfort conditions in category I/A. In this case, global setpoint adjustments or personal comfort systems (PCS) are recommended.

In general, if standard clothing can be a good assumption to design the building HVAC system, clothing adaptation of occupants is a factor of special importance when assessing the indoor environmental quality of a building.

\section{References}

Arens, E., Humphreys, M. A., Dear, R. de, \& Zhang, H. (2010). Are "class A" temperature requirements realistic or desirable? Building and Environment, 45(1), 4-10.

ASHRAE. (2001). International Weather for Energy Calculations (IWEC Weather Files) Users Manual and CD-ROM. Atlanta.

ASHRAE. (2017). Standard 55 - Thermal Environmental Conditions for Human Occupancy. Atlanta.

Atzeri, A. M., Cappelletti, F., Tzempelikos, A., \& Gasparella, A. (2016). Comfort metrics for an integrated evaluation of buildings performance. Energy and Buildings, 127, 411-424.

Baker, N., \& Standeven, M. (1996). Thermal comfort for free-running buildings. Energy and Buildings, 23(3), 175-182.

CEN. (2007). EN 15251 - Indoor environmental input parameters for design and assessment of energy performance of buildings addressing indoor air quality, thermal environment, lighting and acoustics. Brussels.

Cena, K., \& de Dear, R. (1998). Field Study of Occupant Comfort and Office Thermal Environments in a HotArid Climate. Perth.

de Carli, M., Olesen, B. W., Zarrella, A., \& Zecchin, R. (2007). People's clothing behaviour according to external weather and indoor environment. Building and Environment, 42(12), 3965-3973. de Dear, R., \& Brager, G. S. (1998). Developing an Adaptive Model of Thermal Comfort and Preference, 104(4106).

UNI Ente Nazionale Italiano di Unificazione. (1995). 10339 - Air-conditioning systems for thermal comfort in buildings. General classification and requirements Offer, order and supply specifications. Milano.

Fanger, P. O. (1970). Thermal comfort: Analysis and applications in environmental engineering. Copenhagen: Danish Technical Press.

Gauthier, S. M., \& Shipworth, D. (2012). Predictive thermal comfort model: Are current field studies measuring the most influential variables? In Proceedings of the 7th Windsor Conference: The Changing Context of Comfort in an Unpredictable World. Windsor, UK.

Haldi, F., \& Robinson, D. (2008). On the behaviour and adaptation of office occupants. Building and Environment, 43(12), 2163-2177.

Haldi, F., \& Robinson, D. (2011). Modelling occupants' personal characteristics for thermal comfort prediction. International Journal of Biometeorology, 55(5), 681-694.

ISO. (2005). 7730 - Ergonomics of the thermal environment. Analytical determination and interpretation of thermal comfort using calculation of the PMV and PPD indices and local thermal comfort criteria. Geneva.

ISO. (2008). 13790 - Energy performance of buildings. Calculation of energy use for space heating and cooling. Geneva.

La Gennusa, M., Nucara, A., Rizzo, G., \& Scaccianoce, G. (2005). The calculation of the mean radiant temperature of a subject exposed to the solar radiation - A generalised algorithm. Building and Environment, 40(3), 367-375.

Newsham, G. R. (1997). Clothing as a thermal comfort moderator and the effect on energy consumption. Energy and Buildings, 26(3), 283-291.

Newsham, G. R., \& Tiller, D. K. (1995). Field Study of Office Thermal Comfort Using Questionnaire Software.

Schiavon, S., \& Lee, K. H. (2013). Dynamic predictive clothing insulation models based on outdoor air and indoor operative temperatures. Building and Environment, 59, 250-260.

U.S. Department of Energy. (2018). EnergyPlus engineering reference. Version 8.9.0.

Wyon, D. P., \& Holmberg, I. (1972). Systematic observation of classroom behaviour during moderate heat stress. In Proceedings of the CIB Symposium "Thermal Comfort and Moderate heat Stress." Watford, England. 